International Journal of

Molecular Sciences

ISSN 1422-0067

www.mdpi.com/journal/ijms

Article

\title{
The Effect of Sericin from Various Extraction Methods on Cell Viability and Collagen Production
}

\section{Pornanong Aramwit ${ }^{1, *}$, Sorada Kanokpanont ${ }^{2}$, Titpawan Nakpheng ${ }^{3}$ and Teerapol Srichana ${ }^{3}$}

1 Department of Pharmacy Practice, Faculty of Pharmaceutical Sciences, Chulalongkorn University, Bangkok 10330, Thailand

2 Department of Chemical Engineering, Faculty of Engineering, Chulalongkorn University, Bangkok 10330, Thailand; E-Mail: sorada.k@chula.ac.th

3 Department of Pharmaceutical Technology and Drug Delivery System Excellence Center, Faculty of Pharmaceutical Sciences, Prince of Songkla University, Hat Yai, Songkla 90110, Thailand; E-Mails: titpawan@gmail.com (T.N.); teerapol.s@psu.ac.th (T.S.)

* Author to whom correspondence should be addressed; E-Mail: aramwit@gmail.com; Tel.: +66-089-921-7255; Fax: +66-02-218-8403.

Received: 16 April 2010; in revised form: 12 May 2010 / Accepted: 13 May 2010 / Published: 20 May 2010

\begin{abstract}
Silk sericin (SS) can accelerate cell proliferation and attachment; however, SS can be extracted by various methods, which result in SS exhibiting different physical and biological properties. We found that SS produced from various extraction methods has different molecular weights, zeta potential, particle size and amino acid content. The MTT assay indicated that SS from all extraction methods had no toxicity to mouse fibroblast cells at concentrations up to $40 \mu \mathrm{g} / \mathrm{mL}$ after $24 \mathrm{~h}$ incubation, but SS obtained from some extraction methods can be toxic at higher concentrations. Heat-degraded SS was the least toxic to cells and activated the highest collagen production, while urea-extracted SS showed the lowest cell viability and collagen production. SS from urea extraction was severely harmful to cells at concentrations higher than $100 \mu \mathrm{g} / \mathrm{mL}$. SS from all extraction methods could still promote collagen production in a concentration-dependent manner, even at high concentrations that are toxic to cells.
\end{abstract}

Keywords: sericin; cell viability; collagen; extraction; concentration 


\section{Introduction}

Extracellular matrix proteins such as collagen, fibronectin, and gelatin are known to play important roles in the attachment and growth of mammalian cells. We recently showed that silk sericin (SS), a high molecular weight granular protein with adhesive and gelatin-like characteristics, can promote growth of the mouse fibroblast cell line L929, as well as activation of collagen production both in vitro and in vivo [1,2]. Many studies have also demonstrated that SS can accelerate the proliferation and attachment of several mammalian cell lines [3-5], and insect cell culture was also reported to be improved by SS [6]. Moreover, SS added to freezing media as an alternative to fetal bovine serum improved the survival of various cell lines during cryopreservation [7]. However, Terada et al. reported that culture supplemented with $1.0 \%$ SS resulted in no viable cells, which indicates that the presence of $1.0 \%$ SS is harmful to cells [3]. These data demonstrate that the concentration of SS supplemented to culture medium is also a significant factor for cell viability. Nevertheless, the optimal concentration of SS for promoting cell viability has never been reported.

SS can be extracted by various methods, such as high pressure and high temperature techniques, acid or alkaline solutions, or enzyme extraction. The method of extraction significantly affects the biochemical activities of silk proteins. Kurioka et al. reported that acid-degraded, alkali-degraded, and hot water-degraded SS powders exhibit different trypsin inhibitory activities and have different isoelectric points [8]. Furthermore, different SS extraction methods alter its amino acid composition, which may influence its cell-growth and collagen secretion in cells.

The objective of this study was to investigate the chemical properties of SS extracted from Thai silk strains via various extraction methods, which have never yet been investigated. In addition, we determined the effect of various concentrations of SS obtained from the different extraction methods on fibroblast cell viability and collagen production. These data yield important fundamental information for further development of SS as a serum-free medium supplement.

\section{Results and Discussion}

It has long been known that SS can accelerate the proliferation of several cell lines, including hybridoma cells $[3,5,6,9]$. Tsubouchi et al. also reported that SS can enhance the attachment of cultured human skin fibroblasts [4]. The attachment and subsequent proliferation of fibroblast cells are considered to play important roles in the healing process of skin lesions. In this study, the L929 mouse fibroblast cell line has been used as a model to investigate the roles of SS from various extraction methods on cell viability and collagen production.

Recently, SS has been shown to have a protective effect against several toxicities, such as alcoholinduced gastric injury, in animal models [10]. However, the SS used in most previous reports $[3,5,6,9,10]$ was extracted by heat or alkaline solution, even though SS can be extracted by various methods, which affect its physical and biological properties, as shown here. This is the first study to compare the enhancement of cell viability by SS at different concentrations derived by extraction procedures. We found that SS does not have only positive effects on cell viability, as at certain concentrations it starts to induce toxicity. This may be an explanation for the previously reported detrimental effects of SS in clinical uses [11,12]. Moreover, extraction methods also play an important role in SS activity. Many studies have used SS prepared by heat or alkaline extraction and 
have reported the advantageous effects of this protein on cells. This is in agreement with our 3-(4,5-dimethylthiazol-2-yl)-2,5-diphenyltetrazolium bromide (MTT) result, which showed that SS extracted by heat, acid and alkaline solution is rarely toxic to cells at concentrations up to $100 \mu \mathrm{g} / \mathrm{mL}$. Nevertheless, the extraction method has not previously been emphasized in relation to the use of SS, which may lead to confusion, as we have proven that SS derived by urea extraction method was severely toxic to cells. Since SS has been widely investigated for its use in biomedical applications, this point should be clarified in order to avoid misleading interpretation of results.

\subsection{Molecular Weight of SS}

SS extracted by various methods has different molecular weights, as shown in Figure 1. Different extraction methods provided different molecular weight SS, which may result in different chemical and biological properties. SS extracted with urea showed clear bands with molecular weights ranging from 10 to $>225 \mathrm{kDa}$. Sodium dodecyl sulfate polyacrylamide gel electrophoresis (SDS-PAGE) of acid-degraded and alkali-degraded SS showed distinguishable bands within the range of 50-150 kDa and 15-75 kDa, respectively. However, the number of bands from acid-degraded and alkali-degraded SS were much lower than that of SS extracted with urea. SDS-PAGE of SS prepared by the high temperature and high pressure degumming technique showed broad bands, with molecular weights ranging from 25-150 $\mathrm{kDa}$. Our findings are in agreement with those reported by Sprague, which indicates that SS is a mixture of at least 15 different polypeptide chains, ranging in size from 20 to $220 \mathrm{kDa}$ [13].

Figure 1. Molecular weight of SS extracted by various methods. (A) Marker (B) Ureaextracted sericin (C) Heat-degraded sericin (D) Acid-degraded sericin (E) Alkali-degraded sericin.

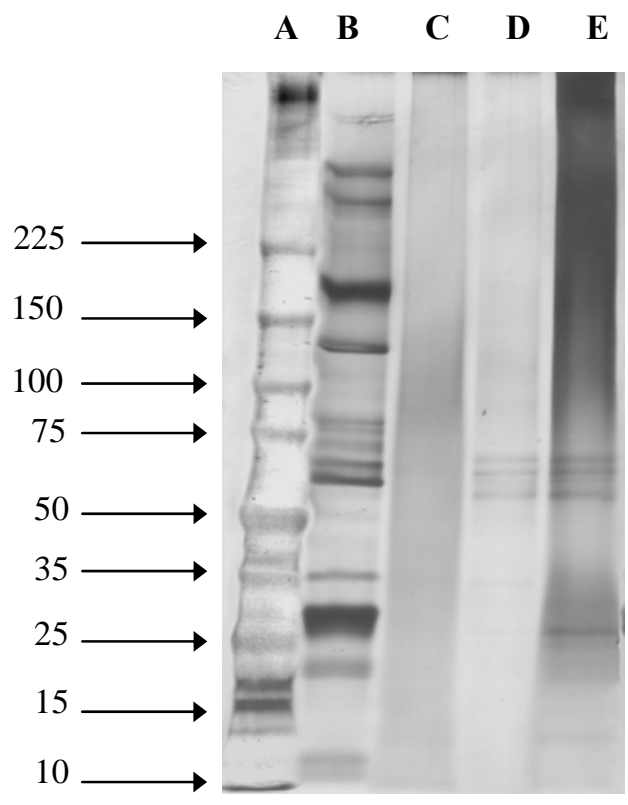

According to these studies, SS from heat, acid, alkaline and urea extraction methods show different molecular weights. This may seem insignificant, but it may in fact reflect biological properties of SS, such as its antimicrobial activity. Other researchers have reported that the antimicrobial property of SS 
is derived from a low molecular weight protein, seroin, from B. mori [14,15]. Seroin is not involved in silk fiber construction and may play a role in protecting silk against microbial degradation [15]. Zurovec et al. reported that seroin polypeptides are present in silk as 22.5 and $23 \mathrm{kDa}$ molecules, and that these polypeptides are liberated from other proteins when silk components are dissolved [14]. The implication of these findings is that urea extraction should be the only method that would provide SS with antimicrobial activity.

\subsection{Particle Size and Zeta Potential Measurement}

Table 1 shows the zeta potential and particle size of SS from different extraction methods. SS from all extraction methods exhibited negative zeta potential values. Zeta potential of SS from urea extraction yielded the highest negative charge, followed by acid-degraded SS, heat-degraded SS and finally alkali-degraded SS. Alkali-degraded SS had the largest particle size, followed by heat-degraded and acid-degraded SS, while SS extracted by urea solution had the smallest particle size. Since ureaextracted SS is present as a very small-sized compound in water, it may be in soluble form, while SS extracted by other methods may be present as hydrocolloids.

Table 1. Zeta potential and particle size of SS from different extraction methods.

\begin{tabular}{ccc}
\hline Extraction method & Zeta potential $(\mathbf{m V})$ & Mean size $(\mathbf{n m})$ \\
\hline Heat & $-20.69 \pm 2.14$ & $110.42 \pm 35.07$ \\
Acid & $-32.12 \pm 5.26$ & $23.80 \pm 16.07$ \\
Alkaline & $-15.87 \pm 2.89$ & $824.42 \pm 86.67$ \\
Urea & $-68.36 \pm 5.67$ & $4.62 \pm 2.44$ \\
\hline
\end{tabular}

Zeta potential is the potential difference between the dispersion medium and the stationary layer of fluid attached to the dispersed particle. The magnitude of the zeta potential gives an indication of the potential stability of the system, where high zeta potentials (either negative or positive) indicates electrically stabilized particles, while colloids with low zeta potentials tend to coagulate or flocculate [16]. From our results, SS obtained from the alkaline extraction method had more of a tendency to coagulate in this solution, which corresponds to the largest particle size. However, SS obtained by heat, acid and urea extraction were stably dispersed with a lower degree of coagulation compared to alkali-degraded SS. Moreover, SS obtained from urea extraction was the most electrically stable and had the least tendency to coagulate, which was confirmed by the smallest mean particle size.

\subsection{Amino Acid Analysis}

Amino acid content in SS extracted from various methods is shown in Table 2. There were slight variations in the amino acid percentage in SS extracted by different methods; however, the main amino acid component in SS was still the same. Serine was the dominant amino acid in SS ( 30\%), while aspartic acid and glycine composed about 10-20\%. The amount of methionine found in heat-degraded SS was significantly higher than in SS extracted by other methods, while the amount of tyrosine found in urea-extracted SS was significantly lower than in SS extracted by other methods. Moreover, heat-extracted SS, which contains the highest amount of methionine and cysteine, sulfur-containing 
amino acids that can generate double-helical structures, can induce the highest levels of collagen production. This result corresponded with our previous report, which showed that methionine in SS relates to its collagen production activity [1].

Table 2. Amino acid composition of SS extracted using various methods (in mole\%).

\begin{tabular}{ccccc}
\hline \multirow{2}{*}{ Amino acid } & \multicolumn{4}{c}{ Extraction method of SS } \\
\cline { 2 - 5 } & Heat & Urea & Acid & Alkaline \\
\hline Asp & 15.64 & 18.31 & 15.93 & 19.88 \\
Ser & 33.63 & 31.27 & 31.86 & 30.01 \\
Glu & 4.61 & 5.27 & 5.75 & 5.93 \\
Gly & 15.03 & 11.23 & 10.49 & 11.01 \\
His & 1.06 & 3.26 & 2.47 & 1.72 \\
Arg & 2.87 & 5.41 & 4.92 & 4.92 \\
Thr & 8.16 & 8.36 & 8.51 & 6.49 \\
Ala & 4.10 & 4.33 & 3.72 & 4.21 \\
Pro & 0.54 & 1.46 & 0.78 & 1.24 \\
Cys & 0.54 & 0.39 & 0.53 & 0.23 \\
Tyr & 3.45 & 0.36 & 5.56 & 5.24 \\
Val & 2.88 & 2.96 & 2.95 & 2.94 \\
Met & 3.39 & 0.12 & 0.06 & 0.15 \\
Lys & 2.35 & 3.14 & 3.48 & 2.89 \\
Ile & 0.56 & 0.96 & 0.87 & 0.75 \\
Leu & 1.00 & 1.58 & 1.43 & 1.56 \\
Phe & 0.28 & 0.60 & 0.71 & 0.81 \\
\hline
\end{tabular}

\subsection{Cytotoxicity of SS Solution}

The MTT assay indicated that SS solutions from all extraction methods had no toxicity to mouse fibroblast cells at concentrations up to $40 \mu \mathrm{g} / \mathrm{mL}$ after $24 \mathrm{~h}$ incubation (Figure 2). It also indicated that heat-degraded and alkali-degraded SS exhibit the least cell toxicity. SS derived from all extraction methods except urea extraction could promote cell viability at low concentrations. SS from urea extraction showed slight toxicity at concentration as low as $60 \mu \mathrm{g} / \mathrm{mL}$ and its toxicity became significant at concentrations higher than $100 \mu \mathrm{g} / \mathrm{mL}$, while SS from other extraction methods showed toxicity to a lesser extent than urea-extracted SS, as shown by the percent viability of fibroblasts. These data indicate that extraction method and SS concentration have significant effects on growth and viability of fibroblast cells.

Heat-degraded SS showed the least toxicity to L929 cells at concentrations up to $100 \mu \mathrm{g} / \mathrm{mL}$, while acid-degraded and alkali-degraded SS showed similar results, but at lower levels of activation, which is consistent with results of other reports [3,5,9]. However, at concentrations higher than $100 \mu \mathrm{g} / \mathrm{mL}$, viability of L929 cells decreased. Similarly, Terada et al. reported that SS from alkaline extraction at low concentrations increased the population in HeLa (human epithelial cell) cultures, while higher concentration of SS (0.3\%) did not [3]. This study also reported that SS at $1.0 \%$ was severely harmful 
to the murine hybridoma (2E3-O) cell line [3]. From these data, we can conclude that concentration and the extraction method of SS, as well as the particular cell line, can affect the cell viability.

Figure 2. Viability study of L929 cells incubated with SS solutions via the MTT assay after incubation for $24 \mathrm{~h}$. Error bars represent the standard error of the mean $(n=3)$. $(\Delta)$ Acid-degraded sericin, (०) Alkali-degraded sericin, (•) Heat-degraded sericin, ( $\boldsymbol{\Delta}$ ) Urea-extracted sericin.

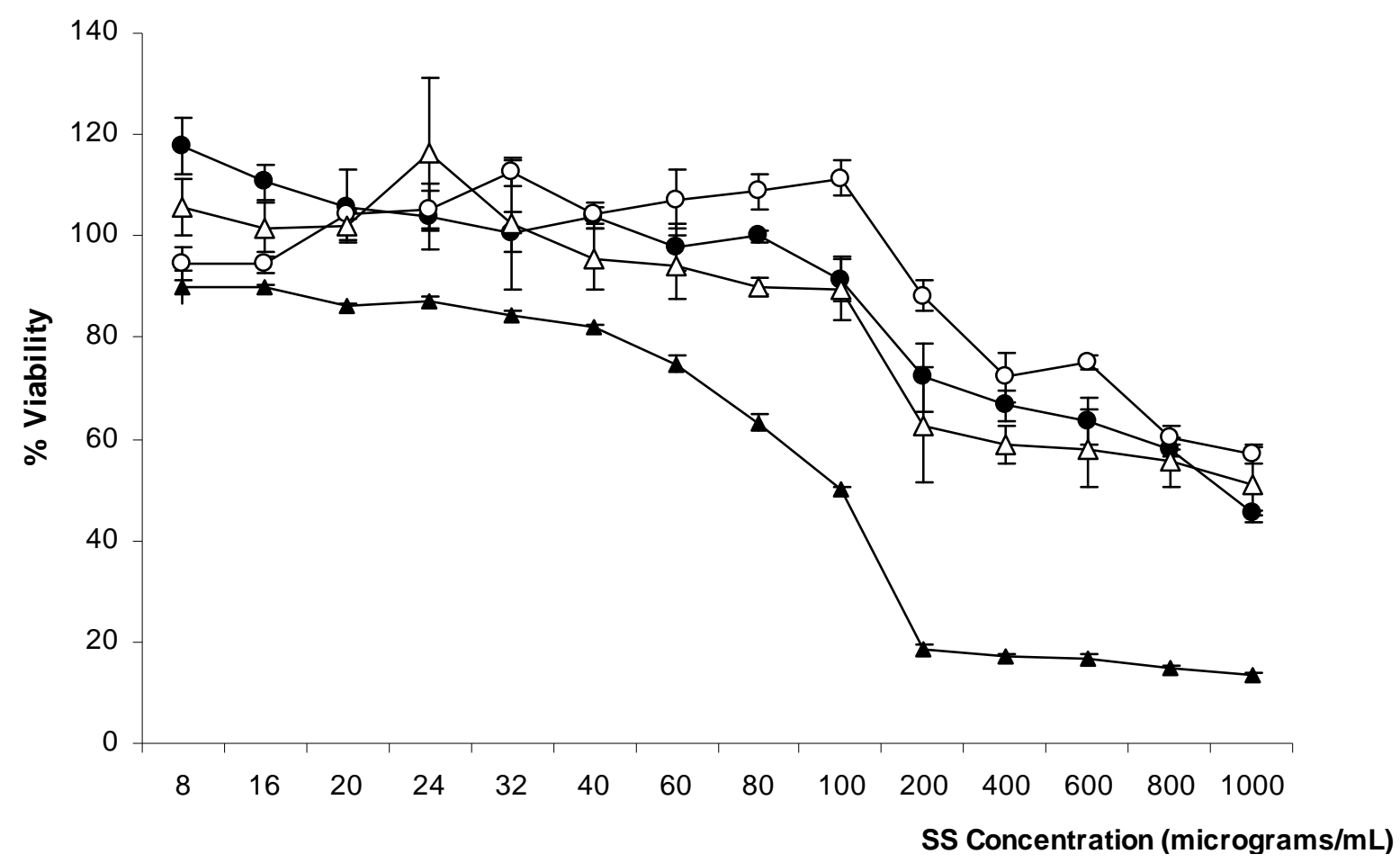

According to our results, the optimum concentration of SS for promoting cell viability depends on the SS extraction method. SS obtained by urea extraction should not be used as a supplement for serum-free medium, since it is toxic to cells. Heat-degraded and alkali-degraded SS are the most suitable for cell culture with the optimum concentration at $100 \mu \mathrm{g} / \mathrm{mL}$. Low concentrations of acid-degraded SS were beneficial to cells. Concentrations as low as $8 \mu \mathrm{g} / \mathrm{mL}$ lead to the greatest cell viability.

\subsection{Adherence of L929 Mouse Fibroblast Cell Line to SS Films}

Since heat-degraded SS significantly promoted cell growth compared to other extraction techniques, and because of its chemical-free property, heat-degraded SS was used to study the adherence of fibroblast cells on SS films. The morphology of L929 mouse fibroblasts cultured on SS heat-extracted films observed at 24, 48, and $72 \mathrm{~h}$ are shown in Figure 3. Cells started attaching to SS films and began proliferating after $24 \mathrm{~h}$ similar to cells on styrene culture plates, which were used as a positive control. Approximately $70 \%$ of cells on both control and SS plate attached to the surface at $48 \mathrm{~h}$ and became confluent after $72 \mathrm{~h}$. After $72 \mathrm{~h}$, cells fully proliferated and formed complete pseudopodia like structures on styrene culture as well as SS plate. Moreover, the number of cells attached on SS plate at $72 \mathrm{~h}$ was slightly higher than number of cells on styrene culture plate. 
Figure 3. Morphology of L929 mouse fibroblasts cultured on polystyrene culture plates and on SS films at $20 \mathrm{X}$ at $24 \mathrm{~h}, 48 \mathrm{~h}$ and $72 \mathrm{~h}$ after cell seeding at 20,000 cells/1,257 $\mathrm{mm}^{2}$.

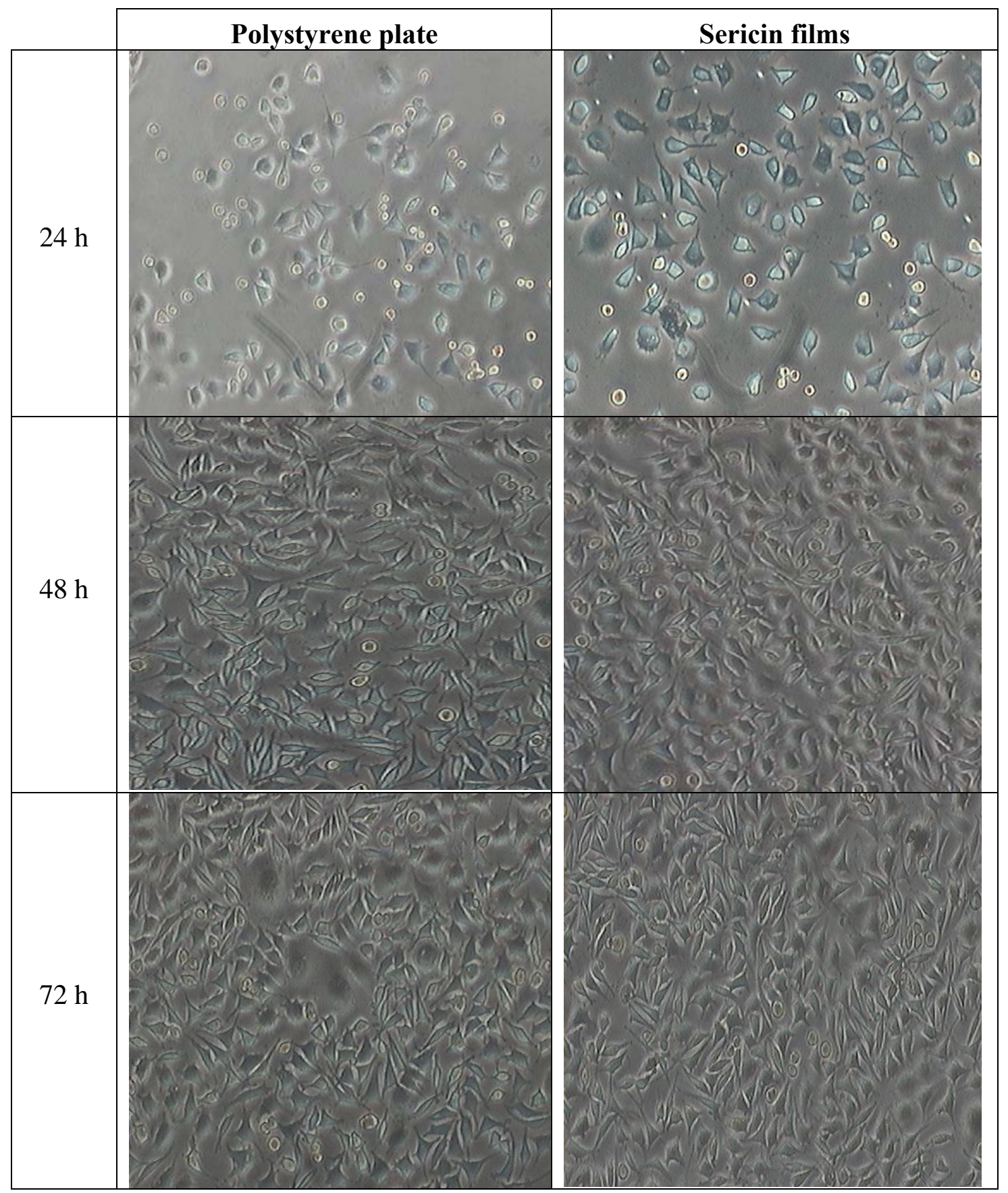

\subsection{Determination of Soluble Collagen Production Induced by SS}

SS extracted by all methods can induce collagen type 1 production from the fibroblast cell line L929 (Figure 4), while the negative control (fibroblast cells without SS as supplement in culture medium) did not produce any collagen (data not shown). However, urea-extracted SS induced the lowest amount of collagen production, compared to SS extracted by the other methods at all concentrations. Heat-degraded SS induced the highest collagen type 1 production at concentrations from 8-200 $\mu \mathrm{g} / \mathrm{mL}$. At concentrations higher than $200 \mu \mathrm{g} / \mathrm{mL}$, alkali-degraded SS could activate the 
highest collagen production. However, alkali-degraded and heat-degraded SS at concentrations higher than $200 \mu \mathrm{g} / \mathrm{mL}$ induced significant levels of collagen type 1, but resulted in fewer viable cells. These data indicate that SS at concentrations higher than $200 \mu \mathrm{g} / \mathrm{mL}$ can induce collagen production, even though it is toxic to cells.

Figure 4. Collagen type 1 production in fibroblast cell line L929 when various SS concentrations were added into the culture medium for $24 \mathrm{~h}$ to make the final concentration of SS in each well 8-1,000 $\mu \mathrm{g} / \mathrm{mL}$, respectively. Error bars represent the standard error of the mean $(n=3)$. $(\Delta)$ Acid-degrade sericin, $(\circ)$ Alkali-degraded sericin, $(\bullet)$ Heat-degraded sericin, ( $\boldsymbol{\Delta}$ ) Urea-extracted sericin.

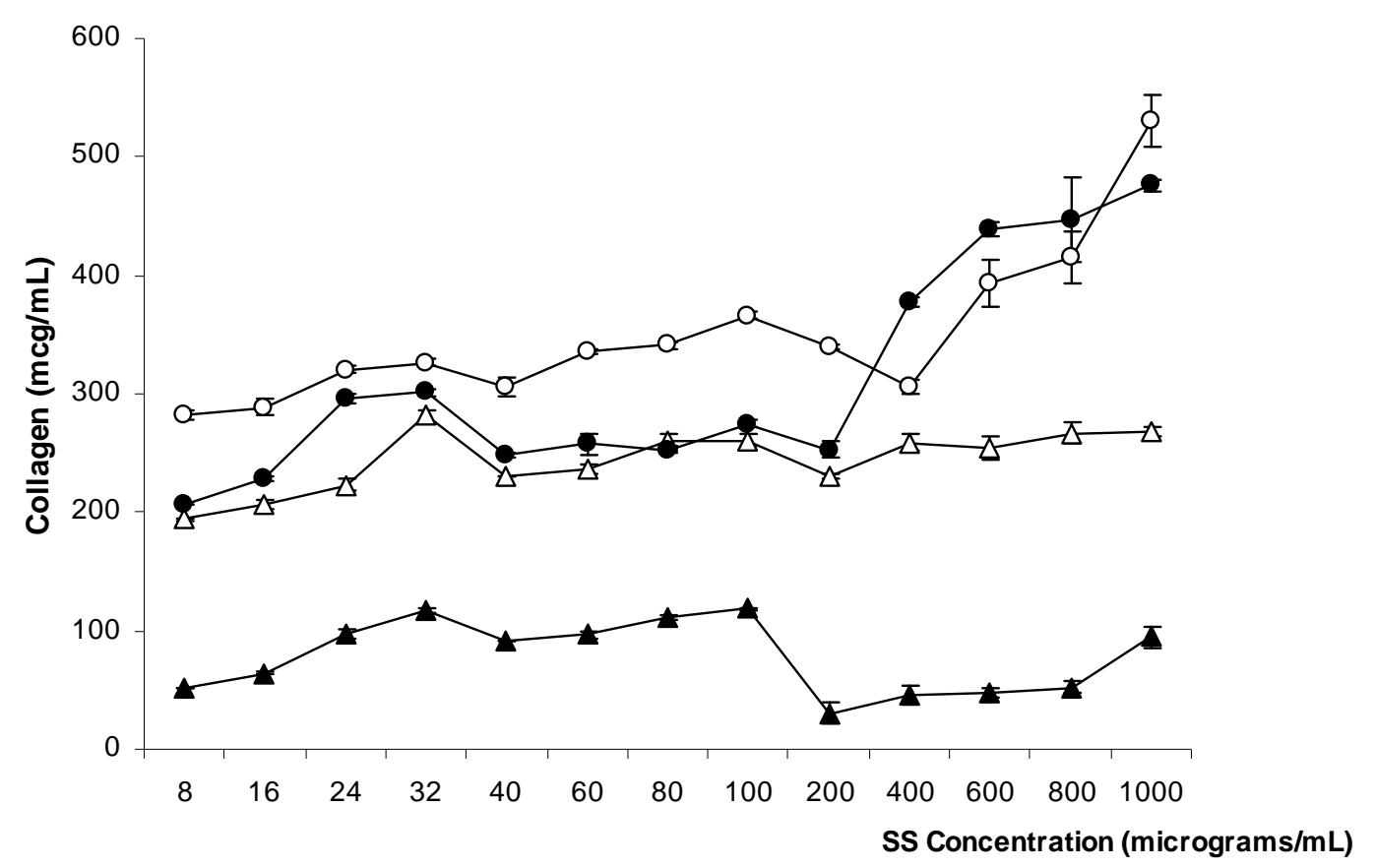

Enhancement of fibroblast collagen production in cells is normally related to transforming growth factor (TGF)- $\beta$ [17], which is generally released only from surviving fibroblast cells $2 \mathrm{~h}$ after cells are activated by chemicals or trauma, and reaching peak levels after $12 \mathrm{~h}$ [18]. This supports our result that collagen content in cell culture still increased at SS concentrations higher than $100 \mu \mathrm{g} / \mathrm{mL}$, even though the percentage of cell viability decreased. Collagen production may be generated from fibroblast cells, which are activated by silk protein at an early stage when most cells are still viable before SS becomes toxic to cells.

\section{Experimental Section}

\subsection{Materials}

\subsubsection{Silkworm Cocoons}

Fresh Bombyx mori cocoons were kindly supplied by Chul Thai Silk Co., Ltd. (Petchaboon province, Thailand). Native Thai silkworms, white cocoons, were produced in a controlled environment. 


\subsubsection{Fibroblast Cell Culture}

The mouse fibroblast cell line L929 (Chinese Academy of Preventive Medical Sciences, Beijing, China) was cultured in Dulbecco Modified Eagle Medium (DMEM) containing 10\% fetal bovine serum (FBS) and antibiotics (100 U penicillin and $100 \mathrm{U}$ streptomycin per $\mathrm{mL}$ ) under $5 \% \mathrm{CO}_{2}$ at $37{ }^{\circ} \mathrm{C}$. The medium was changed every 2 days. When cells reached confluence, they were harvested using $0.25 \%$ trypsin-EDTA $\left(\right.$ Gibco $^{\circledR}$, California, USA), followed by addition of fresh culture medium to create a new single cell suspension for further incubation.

3.1.3. Preparation of SS Powder Using a High Temperature and High Pressure Degumming Technique (Heat-Degraded SS Powder)

Cocoons of $B$. mori silkworms were cut into square pieces and extracted with purified water by autoclaving (SS-320, Tomy Seiko Co., Ltd., Tokyo, Japan) at $120^{\circ} \mathrm{C}$ for $60 \mathrm{~min}$. The aqueous solution obtained from autoclaving silk cocoons was collected and called heat-degraded SS. The aqueous solution was then filtered to remove insoluble material, which is fibroin. After that, the filtrate was frozen and lyophilized using a Heto LL 3000 lyophilizer (Allerod, Denmark) to obtain SS powder. The SS molecular weight from all strains was estimated by SDS-PAGE.

3.1.4. Preparation of SS by Citric Acid and Sodium Carbonate Solution (Acid-Degraded and AlkaliDegraded SS Powders)

Acid-degraded and alkali-degraded SS powders were extracted using a previously described method by Kurioka et al. with some modifications [8]. For acid-degraded SS powder preparations, cocoons were cut and added to a $1.25 \%$ citric acid solution, then boiled for $30 \mathrm{~min}$. After removing insoluble fibers by paper filtration, the clear filtrate was immediately dialyzed in distilled water for three days using cellulose tubing (Cellusep T2, MWCO 6,000-8,000, Sequin, Texas, USA) and distilled water was changed regularly. The $\mathrm{pH}$ of the final solution was measured to verify complete removal of citric acid. The SS solution was then frozen and lyophilized. Alkali-degraded SS powder was prepared similarly, using $0.5 \%$ sodium carbonate solution instead of citric acid.

\subsubsection{Preparation of SS by Urea Solution}

SS extracted by urea solution was prepared using a previously described method with some modifications [4]. Freshly cut cocoon shells were soaked into $8 \mathrm{M}$ urea aqueous solution for $30 \mathrm{~min}$ and then refluxed at $85{ }^{\circ} \mathrm{C}$ for $30 \mathrm{~min}$. Centrifugation and filtration were performed to remove all insoluble residues. The solution was thoroughly dialyzed in distilled water using cellulose tubing (Cellusep T2, MWCO 6,000-8,000, Sequin, Texas, USA) for three days and distilled water was changed regularly. The $\mathrm{pH}$ of final solution was measured to verify complete removal of urea solution. The SS solution was frozen and then lyophilized. 


\subsection{Methods}

\subsubsection{Molecular Weight Determination}

To determine the molecular weight of SS, polyacrylamide gel electrophoresis was performed as previously described with some modifications [19]. Briefly, sample solutions for SDS-PAGE were prepared by adding an equal volume of sample buffer $(0.25 \mathrm{M}$ Tris-HCl, $\mathrm{pH} 7.0$ containing 4\% SDS, $10 \%$ sucrose, $10 \%$ 2-mercaptoethanol, and $0.025 \%$ bromophenol blue) to each protein solution. Each sample solution was then incubated at $98{ }^{\circ} \mathrm{C}$ for 2-3 min and loaded onto a 5\%-20\% gradient gel (Atto Corporation, Tokyo, Japan). Electrophoresis was performed in $125 \mathrm{mM}$ Tris base with $0.96 \mathrm{M}$ glycine and $0.5 \%$ SDS, polypeptide bands were detected by silver staining.

\subsubsection{Particle Size and Zeta Potential Measurement}

The size of self-aggregates was measured by a dynamic light scattering method based on the particle size option in a Zetasizer Nano-ZS (ZEN 3600, Malvern Instruments Ltd., Worcestershire, UK). The scattered intensity was registered at a scattering angle of $90^{\circ}$ at $25{ }^{\circ} \mathrm{C}$. Zeta potentials were measured by a Zetasizer Nano-ZS instrument with palladium-coated electrodes. All samples were adjusted to $\mathrm{pH} 7.0$ prior to particle size and zeta potential measurement. The zeta potential presented is the average value of analyses in triplicate.

\subsubsection{Amino Acid Analysis}

SS amino acid compositions were measured with an amino acid analyzer (Hitachi L-8500A, Tokyo, Japan). Samples were hydrolyzed in $4 \mathrm{M}$ methanesulfonic acid containing 0.2\% 3-(2-aminoethyl) indole (Wako Pure Chemical Industries, Ltd., Tokyo, Japan) at $100{ }^{\circ} \mathrm{C}$ for 24 h under vacuum prior to amino acid analysis. All experiments were performed in triplicate.

\subsubsection{Cytotoxicity of SS Solution}

L929 mouse fibroblast cells at an initial concentration of $2 \times 10^{4}$ cells/well were seeded in a 96-well plate in DMEM containing 10\% FBS. After $24 \mathrm{~h}$, the culture medium was replaced with fresh medium. SS solutions of various concentrations in purified water were filter sterilized by $0.22 \mu \mathrm{m}$ membrane filter (Sartorius Ltd., Epsom, UK) prior to adding to the culture medium to give final SS concentrations in each well at $8.0-1000 \mu \mathrm{g} / \mathrm{mL}$. Cells without SS solution served as negative controls. Melittin, a peptide from bee venom toxin, from 0.125 to $1.0 \mathrm{mg} / \mathrm{mL}$, was used as a positive control. After incubation for $24 \mathrm{~h}$, MTT assay was performed to evaluate cell activity [20]. The absorbance was determined by a microplate reader (Biohit 830, Biohit ${ }^{\circledR}$, Helsinki, Finland) at a wavelength of $570 \mathrm{~nm}$. The percentage of viable cells was calculated and compared to the negative control. All experiments were done in triplicate.

\subsubsection{Adherence of L929 Mouse Fibroblast Cell Line on SS Films}

Heat-degraded SS films were cast from SS solution $(0.1 \% \mathrm{w} / \mathrm{v}$, in water $\mathrm{pH} 5)$ in polystyrene 12-wells cell culture plates (well diameter $20 \mathrm{~mm}$ ). After air-drying, the films were crosslinked by 
ultraviolet (UV) irradiation for $60 \mathrm{~min}$ and sterilized with $70 \%$ ethanol followed by phosphatebuffered saline (PBS, pH 7.5) before seeding cells. L929 mouse fibroblast cells were seeded onto the

sterilized films ( $2 \times 10^{4}$ cells/well). Cells were cultured in DMEM containing 10\% FBS and antibiotics (100 U penicillin and $100 \mathrm{U}$ streptomycin per $\mathrm{mL}$ ) under $5 \% \mathrm{CO}_{2}$ at $37{ }^{\circ} \mathrm{C}$. Cells were harvested at 24, 48 and $72 \mathrm{~h}$, and the morphology of cells on culture plates (control) and on films coated on culture plates were observed by light microscopy (Nikon, TS100, Melville, New York, USA). All experiments were done in triplicate.

\subsubsection{Determination of Soluble Collagen Production Induced by SS}

L929 mouse fibroblast cells were cultured at the same cell content and method as for the cytotoxicity study of SS solution. Cells without SS solution served as a negative control. Supernatants were collected after cell incubation for $24 \mathrm{~h}$. The total amount of soluble collagen type 1 was assayed using the Sircol ${ }^{\circledR}$ collagen assay kit (Biocolor Ltd., Northern Ireland, UK). The results were determined by a microplate reader (Biohit 830, Biohit ${ }^{\circledR}$, Helsinki, Finland) at a wavelength of $500 \mathrm{~nm}$. All experiments were done in triplicate. The amount of collagen was calculated based on a standard curve of soluble collagen (standard bovine collagen type 1, produced from USA disease free animals).

\section{Conclusions}

SS can promote cell viability at certain concentrations, but it can be toxic to cells at higher concentrations. The method of extraction of SS also has significant effects on cell viability. Ureaextracted SS showed the lowest cell viability compared to SS extracted by heat, acid and alkaline methods. Urea-extracted SS was severely harmful to cells at concentrations higher than $100 \mu \mathrm{g} / \mathrm{mL}$. Heat-degraded SS activated the highest collagen production, while urea-extracted SS showed the lowest level of collagen activation. SS from all extraction methods could still promote collagen production in a concentration-dependent manner, even at high concentrations that are toxic to cells, which indicate that collagen was generated before fibroblast cells departed.

\section{Acknowledgements}

This research was supported by The National Research Council of Thailand and Thailand Research Fund.

\section{References and Notes}

1. Aramwit, P.; Kanokpanont, S.; De-Eknamkul, W.; Kamei, K.; Srichana, T. The effect of sericin with variable amino-acid content from different silk strains on the production of collagen and nitric oxide. J. Biomater. Sci. Polym. Ed. 2009, 20, 1295-1306.

2. Aramwit, P.; Sangcakul, A. The effects of sericin cream on wound healing in rats. Biosci Biotechnol. Biochem. 2007, 71, 2473-2477.

3. Terada, S.; Nishimura, T.; Sasaki, M.; Yamada, H.; Miki, M. Sericin, a protein derived from silkworms, accelerates the proliferation of several mammalian cell lines including a hybridoma. Cytotechnology 2002, 40, 3-12. 
4. Tsubouchi, K.; Igarashi, Y.; Takasu, Y.; Yamada, H. Sericin enhances attachment of cultured human skin fibroblasts. Biosci. Biotechnol. Biochem. 2005, 69, 403-405.

5. Terada, S.; Sasaki, M.; Yanagihara, K.; Yamada, H. Preparation of silk protein sericin as mitogenic factor for better mammalian cell culture. J. Biosci. Bioeng. 2005, 100, 667-671.

6. Takahashi, M.; Tsujimoto, K.; Yamada, H.; Takagi, H.; Nakamori, S. The silk protein, sericin, protects against cell death caused by acute serum deprivation in insect cell culture. Biotechnol. Lett. 2003, 25, 1805-1809.

7. Sasaki, M.; Kato, Y.; Yamada, H.; Terada, S. Development of a novel serum-free freezing medium for mammalian cells using the silk protein sericin. Biotechnol. Appl. Biochem. 2005, 42, 183-188.

8. Kurioka, A.; Kurioka, F.; Yamazaki, M. Characterization of sericin powder prepared from citric acid-degraded sericin polypeptides of the silkworm, Bombyx Mori. Biosci. Biotechnol. Biochem. 2004, 68, 774-780.

9. Ogawa, A.; Terada, S.; Kanayama, T.; Miki, M.; Morikawa, M.; Kimura, T.; Yamaguchi, A.; Sasaki, M.; Yamada, H. Improvement of islet culture with sericin. J. Biosci. Bioeng. 2004, 98, 217-219.

10. Li, Y.G.; Ji, D.F.; Lin, T.B.; Zhong, S.; Hu, G.Y.; Chen, S. Protective effect of sericin peptide against alcohol-induced gastric injury in mice. Chin. Med. J. (Engl.) 2008, 121, 2083-2087.

11. Mason, R. Fabrics for atopic dermatitis. J. Fam. Health Care 2008, 18, 63-65.

12. Koller, D.Y.; Halmerbauer, G.; Bock, A.; Engstler, G. Action of a silk fabric treated with AEGIS in children with atopic dermatitis: A 3-month trial. Pediatr. Allergy Immunol. 2007, 18, 335-338.

13. Sprague, K.U. The Bombyx mori silk proteins: Characterization of large polypeptides. Biochemistry 1975, 14, 925-931.

14. Zurovec, M.; Yang, C.; Kodrik, D.; Sehnal, F. Identification of a novel type of silk protein and regulation of its expression. J. Biol. Chem. 1998, 273, 15423-15428.

15. Nirmala, X.; Kodrik, D.; Zurovec, M.; Sehnal, F. Insect silk contains both a Kunitz-type and a unique Kazal-type proteinase inhibitor. Eur. J. Biochem. 2001, 268, 2064-2073.

16. Zeta Potential of Colloids in Water and Waste Water, ASTM Standard D 4187-82; American Society for Testing and Materials: West Conshohocken, PA, USA, 1985.

17. Franz, M.G.; Kuhn, M.A.; Nguyen, K.; Wang, X.; Ko, F.; Wright, T.E.; Robson, M.C. Transforming growth factor beta(2) lowers the incidence of incisional hernias. J. Surg. Res. 2001, 97, 109-116.

18. Henry, G.; Garner, W.L. Inflammatory mediators in wound healing. Surg. Clin. North. Am. 2003, 83, 483-507.

19. Takasu, Y.; Yamada, H.; Tsubouchi, K. Isolation of three main sericin components from the cocoon of the silkworm, Bombyx mori. Biosci. Biotechnol. Biochem. 2002, 66, 2715-2718.

20. Mosmann, T. Rapid colorimetric assay for cellular growth and survival: Application to proliferation and cytotoxicity assays. J. Immunol. Methods 1983, 65, 55-63.

(C) 2010 by the authors; licensee MDPI, Basel, Switzerland. This article is an Open Access article distributed under the terms and conditions of the Creative Commons Attribution license (http://creativecommons.org/licenses/by/3.0/). 